Department, National Hospital, for preparing all the illustrations.

REFERENCES

Anderson, R. McD., and Blackwood, W. (1959). J. Path. Bact. 77. 101

Biumi, F. (1765). Observationes Anatomicae. Milan.

Brunton, W. (1851). Trans. path. Soc. Lond., 3, 47.

Brolin, S. E., and Hassler, O. (1958). Acta path. microbiol. scand., 44, 59

Bull, J. W. D. (1962). Lond. Clin. med. J., 3, 47.

Collier, J. (1922). In $A$ Textbook of the Practice of Medicine, edited by F. W. Price. Frowde and Hodder and Stoughton, London.

Crawford. T. (1959). J. Neurol. Neurosurg. Psychiat., 22, 259.

Dandy, W. E. (1944). Intracranial Arterial Aneurysms. Comstock Publ., New York.

Engeset, A. (1944) Acta radiol. (Stockh.), Suppl. No. 56.

Forbus, W. D. (1930). Bull. Johns Hopk. Hosp., 47, 239.

Glynn, L. E. (1940). J. Path. Bact.. 51, 213.

Greitz, T., and Lindgren, E. (196i). In Angiography, edited by H. L. Ahrams. (hurchill, London.

Harris, P., and Udvarhelyi, G. B. (1957). J. Neurosurg., 14, 180.

Hassler, O. (1961). Acta psychiat. scand., Suppl. No. 154

Jefferson, G. (1938). Brit. J. Surg., 26, 267.
McDonald, C. A., and Korb, M. (1939). Arch. Neurol. Psychiat. (Chic.), 42, 298.

McKinney, J. M., Acree, T., and Soltz, S. E. (1936). Bull. neurol. Inst. N.Y., 5, 247.

Meadows, S. P. (1951). "Intracranial Aneurysms" in Modern Trends in Neurology, edited by A. Feiling. Butterworths, London

Moniz, E (1927). Rev. neurol., 34, 1927.

Mourgues, G. (1954). Ärztl. Wschr., 9, 417.

Padget, D. H. (1948). Carnegie Contrib. Embryol., 32, 205.

Paterson, J. H., and McKissock, W. (1956). Brain, 79, 233.

Perrett, L. V., and Bull, J. W. D. (1959). Brit. J. Radiol., 32, 85 Poppen, J. L. (1951). J Neurosurg., 8,75

Rischbieth, R. H. C., and Bull, J. W. D. (1958). Brit. J. Radiol., 31, 125 .

Robertson, E. G. (1949). Brain, 72, 150.

Shennan, T. (1934). Spec. Rep. Ser. med. Res. Coun. (Lond.), No. 193.

Stehbens, W. E. (1954). Aust. Ann. Med., 3, 214.

Symonds, C. P. (1923). Guy's Hosp. Rep., 73, 139.

Meadows, S. P., and Taylor, J. (1937). Brain, 60, 52.

Tomlinson, B. E. (1959). J. clin. Path., 12, 391

Van 't Hoff, W., Hornabrook, R. W., and Marks, V. (1961). Brit med J, 2, 1190.

Wolman, L. (1959). Brain, 82, 276.

\title{
COMPARISON OF CORTICOSTEROID AND SULPHASALAZINE THERAPY IN ULCERATIVE COLITIS
}

\begin{abstract}
S. C. TRUELOVE, M.D., F.R.C.P.
Nuffield Department of Clinical Medicine, Radcliffe Infirmary, Oxford

No perfect treatment of ulcerative colitis exists. Nevertheless a number of measures are known to be beneficial in an attack of the disease, and they fall into two main groups. On the one hand, certain general medical measures are plainly beneficial when circumstances demand them; the most important ones are correction of dehydration and electrolyte deficiencies, blood transfusions to combat loss of blood, a nutritious diet containing ample protein to minimize wasting, and vitamin supplements to guard against deficiencies. On the other hand, a large number of drugs have been employed because of some evidence that they may bring the attack swiftly to an end. We know of only two types of therapeutic agent for which there is strong evidence that they promote the chance of rapid termination of the attack. They are the corticosteroids and
\end{abstract}

BY GEOFFREY WATKINSON,* M.D., F.R.C.P.
Consultant Physician, York Hospitals, York

GERALD DRAPER, B.A.

Unit of Biometry, University of Oxford sulphasalazine respectively.

\section{Corticosteroid Treatment}

Shortly after the discovery by Hench et al. (1949) of the beneficial symptomatic actions of cortisone in rheumatoid arthritis, reports began to appear of the use of this agent and of A.C.T.H. in ulcerative colitis. The early reports were conflicting, but a large-scale controlled therapeutic trial showed that cortisone increased the chance of clinical remission within six weeks of starting medical treatment (Truelove and Witts, 1954, 1955). A second therapeutic trial showed that A.C.T.H. was similar to cortisone in the treatment of first attacks but was superior to cortisone in relapses of established disease, although at the price of more complications of therapy (Truelove and Witts, 1959). The newer corticosteroids have been extensively used

*Formerly Senior Lecturer in Medicine, Leeds University, during the time when most of this study was being made. in the treatment of ulcerative colitis, but it is questionable whether they are markedly superior to cortisone in equivalent doses, at any rate so far as can be judged from comparing published results (Watkinson, 1960).

Another way of using corticosteroids in this disease is to apply them topically to the colon. After preliminary studies had given encouraging results (Truelove, 1956, 1957) two independent controlled therapeutic trials employing a "double-blind " technique yielded unequivocal evidence that this form of treatment was beneficial (Truelove, 1958; Watkinson, 1958).

These two methods of using corticosteroids can be combined, and there is evidence that this enhances the therapeutic effect (Truelove, 1960).

\section{Sulphasalazine Treatment}

Sulphasalazine was first used for the treatment of ulcerative colitis by Svartz, who has written a number of articles on its use (Svartz, 1942, 1948, 1954, 1956, 1960). Another Scandinavian physician who has advocated its use is Lagercrantz $(1949,1955)$, who has employed it extensively in children with the disease. About 1950 the drug began to be used in America, under the name of "azopyrin," which was later changed to "asulfidine," and many favourable reports have come from physicians there (Morrison, 1952, 1953 ; Bargen, 1955 ; Moertel and Bargen, 1959).

Sulphasalazine ("salazopyrin ") is an azo-compound of salicylic acid and sulphapyridine. Like other acid azo-compounds, it has a pronounced affinity for connective tissue, as has been shown by fluorescent microscopy (Svartz, 1960). It is a brown powder which is prescribed in the form of tablets, each containing $0.5 \mathrm{~g}$., for oral use. For an acute attack of ulcerative colitis it is usually employed in a dose of 1-2 g. four 
times a day. Occasional patients can tolerate larger doses of up to $12 \mathrm{~g}$. a day in divided doses.

A considerable number of patients experience vomiting with the larger doses. Less common, but more serious, toxic effects are fever, drug rashes, and blood dyscrasias.

\section{Present Study}

The main object of this study was to compare combined topical and systemic corticosteroid therapy with sulphasalazine in terms of their efficacy in cutting short an attack of ulcerative colitis.

Dosages.-Combined corticosteroid therapy consisted of oral prednisolone $5 \mathrm{mg}$. four times a day and a nightly rectal drip of $100 \mathrm{mg}$. of hydrocortisone succinate sodium in solution. The rectal drip was prepared by dissolving one hydrocortisone (" ef-Cortelan solution ") tablet in approximately $150 \mathrm{ml}$. of tap-water. Sulphasalazine treatment consisted in the administration of $0.5 \mathrm{~g}$. tablets in a dose of $2 \mathrm{~g}$. four times a day for the first week, followed by $1 \mathrm{~g}$. four times a day for the second.

Selection of Cases. - The cases were all examples of classical ulcerative colitis but without complications which might demand other types of therapy. All were suffering from a frank attack of the disease at the time of admission to the therapeutic trial.

Assessment of Effect of Therapy.-The effects of therapy were assessed on clinical and sigmoidoscopic evidence. (a) Clinical Assessment : At the end of two weeks' treatment those patients who were completely symptom-free were classed as successes. All others were classed as having failed to achieve a rapid clinical remission. (b) Sigmoidoscopic Responses: The sigmoidoscopic appearances at the beginning of treatment were graded according to the criteria we have used in previous therapeutic trials. At the end of two weeks' treatment sigmoidoscopy was repeated and a definite improvement was classed as a successful sigmoidoscopic response. (In the case of the Leeds patients these sigmoidoscopic assessments were made by an independent observer, Professor J. C. Goligher.)

\section{The Statistical Method}

The sequential method of Armitage (1957) was used. The essential feature of sequential methods is that the sample size depends on the results obtained as the trial progresses, and is not decided in advance as is the case with classical statistical tests.

The patients were paired, one patient in each pair receiving corticosteroids and the other sulphasalazine. The results for those pairs in which one treatment was successful according to an agreed criterion and the other was not (the "untied pairs") were plotted on a chart as shown in Figs. 1 and 2 . If one treatment is superior the plotted line will tend towards either the upper or the lower boundary. The trial is halted when it reaches one of these boundaries or the central one. When this occurs we may make one of the following assertions: (1) Upper boundary is reached: corticosteroid therapy is superior. (2) Lower boundary is reached: sulphasalazine is superior. (3) Central boundary is reached: no difference between treatments.

The combined probability of (1) or (2) occurring if there is in fact no difference between the treatments is 0.05 -that is, we were making a significance test at the conventional $5 \%$ level.

\section{Random Allocation of Treatments to Patients}

Each patient from Oxford was paired with another from Oxford and patients from Leeds were similarly paired together. Treatments were allocated randomly at each centre, using a method of restricted randomization which ensured that at no time did the number of patients having had one treatment greatly exceed the number having had the other. This was achieved by preparing in advance a treatment allocation sheet in which each treatment was randomly assigned to patients in such a way that each successive group of six patients contained three patients on one treatment and three on the other. The physicians were of course not aware of the sequence of treatments on these lists.

\section{Results}

Two separate charts were used in recording the progress of the trial. The patients in each pair were compared separately on clinical and on sigmoidoscopic criteria and the results plotted on Figs. 1 and 2 respectively in those cases where the pairs were "untied" according to the appropriate criterion. Results from Oxford and Leeds were taken together and plotted in

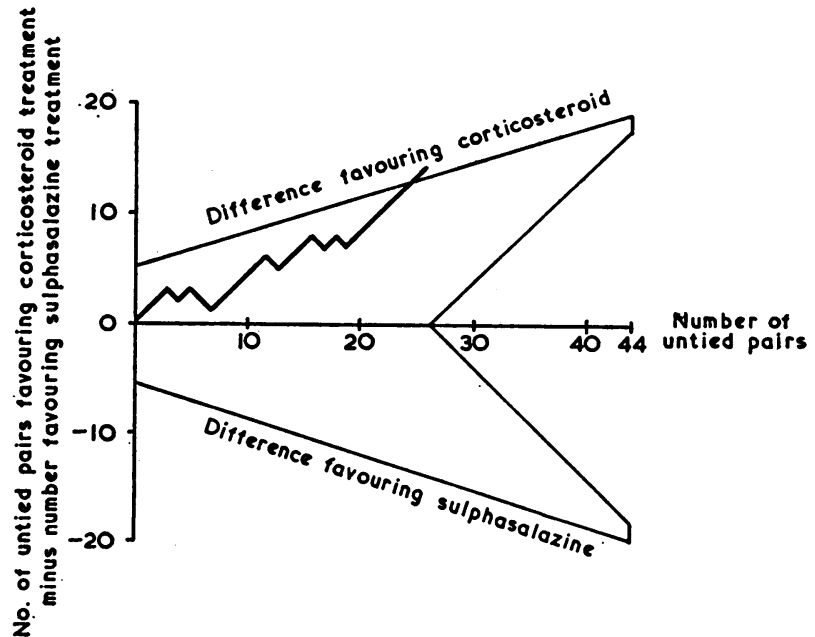

FIG. 1.-Sequential analysis chart showing that combined topical and systemic corticosteroid therapy is more likely than sulphasalazine to induce rapid symptomatic remissions.

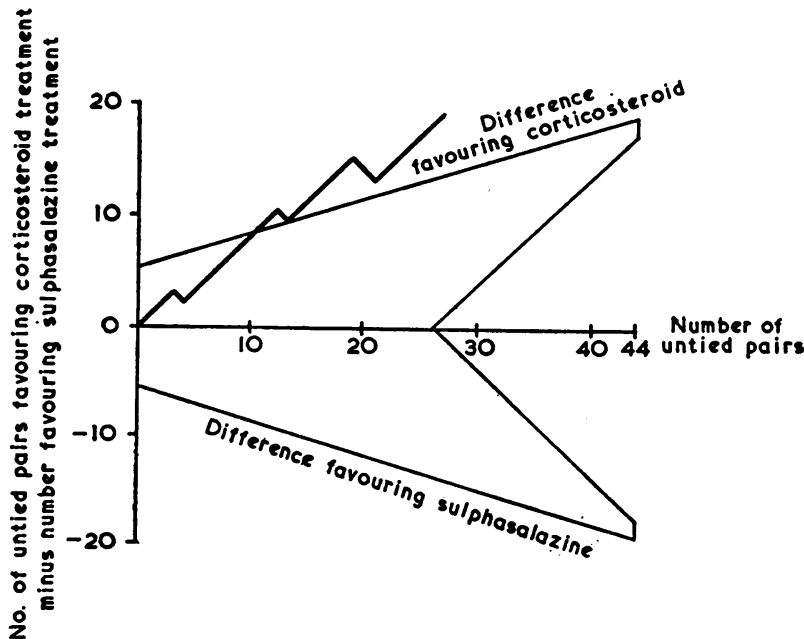

FIG. 2.-Sequential analysis chart showing that combined topical and systemic corticosteroid therapy is more likely than sulphasalazine to bring about early reduction in colonic mucosal inflammation as judged by the sigmoidoscopic appearances. 
chronological order as determined by the date of entry into the trial of the second patient of the pair.

It will be observed that on the sigmoidoscopic criterion a result in favour of corticosteroids was obtained comparatively early. However, the trial was continued until a result was obtained on the clinical criterion also. This also showed a difference in favour of corticosteroids.

The completed sequential analysis charts show whether one treatment is superior to another but give little idea of the proportion of successful treatments owing to the fact that "tied pairs" are not charted. The overall results for the two treatments tested are given in the Table.

Percentage of Rapid Clinical and Sigmoidoscopic Responses in Two Treatment Groups at End of Two-weeks Trial Period

\begin{tabular}{c|c|c|c|c}
\hline & \multicolumn{2}{|c|}{ Clinical Results } & \multicolumn{2}{|c|}{ Sigmoidoscopic Results } \\
\cline { 2 - 5 } Treatment & $\begin{array}{c}\text { No. of } \\
\text { Patients }\end{array}$ & $\begin{array}{c}\text { No. in } \\
\text { Remission }\end{array}$ & $\begin{array}{c}\text { No. of } \\
\text { Patients }\end{array}$ & $\begin{array}{c}\text { No. } \\
\text { Showing } \\
\text { Sigmoidoscopic } \\
\text { Improvement }\end{array}$ \\
\hline $\begin{array}{l}\text { Combined corticosteroids } \\
\text { Sulphasalazine .. }\end{array}$ & 58 & $\begin{array}{l}44(76 \%) \\
31(52 \%)\end{array}$ & $\begin{array}{c}58 \\
60 *\end{array}$ & $\begin{array}{c}45(78 \%) \\
26(43 \%)\end{array}$ \\
\hline
\end{tabular}

* Includes two patients admitted to the trial in the closing stages who had not yet been paired with corticosteroid-treated patients when the sequential analysis brought the trial to an end.

\section{Complications of the Disease During the Trial Period}

These were few, and consisted of the following. Corticosteroid group: In one instance the disease pursued a fulminating course and the patient was brought to emergency colectomy. Sulphasalazine group : Two patients developed colitic arthritis, but there was improvement during treatment. One patient showed evidence of severe malnutrition and abnormal liver function:

\section{Complications of Therapy}

The corticosteroid-treated patients had negligible complications-one patient suffering from nausea and anorexia attributed to treatment.

The sulphasalazine group showed a high incidence of symptoms which were attributed to side-effects of treatment, namely:

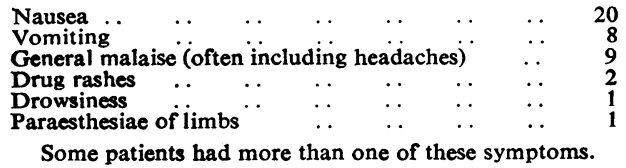

It can be seen that nausea, vomiting, and general malaise were common. These effects were usually relieved when the dose was reduced to $4 \mathrm{~g}$. daily, but occasional patients required even further reduction to eliminate them.

Two examples of drug rashes occurred. One patient had a macular eruption which developed 10 days after starting sulphasalazine and disappeared a few days after stopping it. The second suffered from a generalized scarlatiniform rash in the second week of treatment, the rash disappearing soon after the sulphasalazine was stopped.

There were no examples of dangerous complications such as severe blood dyscrasias.

\section{Discussion}

This trial has shown that, as judged by the proportion of attacks of ulcerative colitis which are rapidly checked, combined topical and systemic corticosteroid treatment at a dosage level which appears to be virtually free from side-effects is superior to sulphasalazine in full dosage.

Several points are immediately worth making. First, it can be taken that sulphasalazine is a useful agent in ulcerative colitis. When dummy treatments have been used by us in the past, the results have been bad and a negligible proportion of patients so treated have achieved a rapid clinical remission (Truelove, 1958; Watkinson, 1958). In the present study it required the admission of a large number of patients into the trial before combined corticosteroid treatment emerged as the significantly better treatment. Secondly, the present trial probably underestimates the difference between combined corticosteroid and sulphasalazine therapy. The corticosteroids were used in a relatively low dose which has become a standard out-patient regime at Oxford because of its safety when used for short periods of only a few weeks, whereas patients ill enough to be admitted to hospital are usually treated with double the dosage employed in the trial. By contrast, the dose of sulphasalazine was ill-tolerated by many of the patients, so that it can be inferred that it was being employed at or near to its maximum dose. Thirdly, corticosteroids and sulphasalazine can be combined. This combination has appeared to us to be a useful one in our ordinary clinical practice, but additional controlled trials will be necessary to settle the issue.

Every controlled therapeutic trial has its limitations because only a few points can be firmly settled in a single trial. We must therefore emphasize that the present study merely shows that combined corticosteroid treatment is better than sulphasalazine for rapidly checking an attack of the disease. Extrapolation from these results to embrace treatment over more prolonged periods of time would be wrong. The need for caution can be illustrated by the results of a controlled therapeutic trial carried out by Lennard-Jones et al. (1960) in which oral prednisolone was initially sharply superior to sulphasalazine but with more prolonged treatment the difference was much reduced. Nevertheless, since an attack of ulcerative colitis is always unpleasant for the patient and may at any moment threaten his life, it is important to determine the best combination of available therapeutic agents for checking an acute attack as quickly as possible. In this respect combined corticosteroid treatment appears at present to be the method of choice.

AdDENDUM.-After the completion of the present study Baron et al. (1962) published the results of a formal therapeutic trial which showed sulphasalazine to be effective in the majority of patients with mild attacks of ulcerative colitis, although a closely related compound, salicylazosulphadimidine, appeared to be of little benefit.

\section{Summary}

A therapeutic trial has been carried out to determine the relative efficacy of combined oral and topical corticosteroid therapy and sulphasalazine in terms of their ability to terminate swiftly an attack of ulcerative colitis.

The experimental design involved the use of the restricted sequential method of Armitage.

Patients with a frank attack of ulcerative colitis were allotted at random to treatment either with combined corticosteroids or with sulphasalazine. Fifty-eight patients were treated by combined corticosteroids and 60 by sulphasalazine. The results of treatment were 
assessed after two weeks. Clinical "success" was defined as complete freedom from symptoms, and sigmoidoscopic "success" was defined as a definite improvement in the sigmoidoscopic appearances.

By both these criteria, combined corticosteroid treatment emerged as superior to sulphasalazine for the limited purpose which this therapeutic trial was designed to test.

\section{REFERENCES}

Armitage, P. (1957). Biometrika, 44, 9.

Bargen, J. A (1955). Sth. med. J. (Bgham. Ala.), 48, 192.

Baron, J. H., Connell, Lennard-Jones, J. E, and Jones, F. A. (1962). Lancet, 1, 1094.

Hench, P. S., Kendall, E. C., Slocumb, C. H., and Polley, H. F. (1949). Ann. rheum. Dis., 8, 97.

Lagercrantz, R. (1949). Acta paediat. (Uppsala), Suppl. No. 75, p. 89

_ (1955). Ibid., 44, 302.
Lennard-Jones, J. E., Longmore, A. J., Newell, A. C., Wilson, C. W. E., and Jones, F. A. (1960). Gut, 1, 217

Moertel, C. G., and Bargen, J. A. (1959). Ann. intern. Med., 51 879 .

Morrison, L. M. (1952). Gastroenterology, 21, 133.

(1953). J. Amer. med. Ass., 151, 366.

Svartz, N. (1942). Acta med. scand., 110, 577.

(1948). Ibid., 130, Suppl. No. 206, p. 465

(1954). Gastroenterology, $26,26$.

(1956). Gastroenterologia (Basel), 86, 683

(1960). Groceedings of International Congress of Gastro

enterology, Leyden. Published by Excerpta Medica.

Truelove, S. C. (1956). Brit. med. J., 2, 1267.

- (1957). Ibid., 1, 1437.

(1958). Ibid., 2, 1073.

(1960). Ibid., 1, 464.

and Witts, L. J. (1954). Ibid., 2, 375.

$=-(1955)$. Ibid., 2, 1041.

Watkinson, G. (1958). Ibid., 2, 1077.

(1960). Proceedings of International Congress of Gastroenterology, Leyden. Published by Excerpta Medica.

\title{
INTRAVENOUS UREA AS A DIURETIC IN PROSTATECTOMY
}

BY

\author{
G. B. McKELVIE, M.B., F.R.C.S.Ed. \\ Senior Surgical Registrar, Stirling Royal Infirmary
}

The two greatest hazards of prostatectomy are generally acknowledged to be post-operative haemorrhage and infection. The Lancet (1956) stated that there were "three potential killers" after prostatectomy-bleeding, infection, and "collapse of the patient's morale." The third of these causes is probably the result in large measure of the first two.

It was thought likely that if a large urinary output could be achieved safely in the immediate postoperative period a big contribution to the elimination of these hazards would be made. With this end in view it was decided to perform a series of prostatectomies using intravenous urea as a diuretic combined with a simple closed-drainage system.

\section{Methods and Materials}

In a period of 13 months up to July, 1962, 161 prostatectomies have been performed in the urological unit at Stirling Royal Infirmary and Clackmannan County Hospital. They presented either as emergencies with retention of urine (70 with acute retention and 20 with chronic retention) or were admitted from the waiting-list after previous investigation at an out-patient clinic (71 cases).

It is noteworthy that only four patients in this 13month period were not considered fit to undergo prostatectomy. All four died within a few hours or days of admission from causes not directly related to retention of urine. The operability rate was therefore $97.5 \%$.

The average age of the patients was 71, ranging from 56 to 91 , with 29 octogenarians in the series. As no selection was made, the series therefore contains a representative quota of patients suffering from vascular disease, hypertension, chronic bronchitis, and anaemia. Indeed, there was a definite history of previous myocardial infarction in 20 cases -17 suffered from congestive cardiac failure (eight controlled with digitalis and nine noted after admission) and in three there had been cerebral thrombosis with only partial recovery of function. Other complicating factors included seven patients with mild diabetes, 19 with a history of duodenal ulceration, one admitted with acute retention of urine and subacute intestinal obstruction which had to be dealt with first, one had carcinoma of the oesophagus brought to notice after operation, one had previously undergone nephrectomy for staghorn calculus, and one was known to have gross bilateral hydronephrosis. The type of operation performed was retropubic in 133 cases, transvesical in 15, and perurethral in 13.

Immediate prostatectomy was performed in 48 of the 70 patients who presented with acute retention of urine and in 4 of the 14 who presented with chronic retention with overflow. The operation and histological findings were: benign hypertrophy in 143 cases, carcinoma in 12 , fibrous prostate in 5, and large prostatic abscess in 1.

In all cases general anaesthesia was used and blood transfusion was given to replace loss at the time of operation. In 39 cases blood transfusion was not required, 67 had 1 pint $(570 \mathrm{ml}$.), 44 had 2 pints $(1,140$ $\mathrm{ml}$.), the remaining 11 having 3 pints $(1,700 \mathrm{ml}$.) or more, either on account of severe preoperative anaemia or rather more than average loss at operation.

Antibiotics were not used as a routine, but where infection was known to be present or where respiratory complications were expected the appropriate antibiotic was given. Eighty-nine patients had no antibiotic at all.

The Routine.-In 110 cases $3,000 \mathrm{ml}$. of $4 \%$ urea in $5 \%$ dextrose " ureaphil" was given intravenously in 24 hours for 72 hours post-operatively. In three cases where troublesome bleeding was expected this was increased to $4,000 \mathrm{ml}$. in 24 hours; the remaining 48 had $3,000 \mathrm{ml}$. in 24 hours for 48 hours post-operatively. A "polythene" catheter of the "intracath" type was found to be satisfactory in keeping the intravenous transfusion running for 72 hours with the minimum of trouble, and when fitted with a "plexitron" adaptor allowed blood tranusfusion to be given simultaneously. The transfusion of urea was started in the theatre as soon as the prostate gland had been removed.

The urethral catheter used was a Foley self-retaining type made of plastic, and at the end of operation, after washing the bladder with a weak solution of chlorhexidine, this was connected to a gamma-ray sterilized disposable plastic bag of $1,500-\mathrm{ml}$. capacity, thereby 